\title{
González Palacios, Carlos (comp.). Reflexiones sobre la democracia y el Estado de derecho en el mundo contemporáneo. Lima: ESAN, 2020
}

\section{Por María Victoria Calero Ponce}

Estudiante de la carrera de Derecho Corporativo de la Universidad ESAN

Esta obra es un importante esfuerzo de recopilación - y en la mayoría de casos, de traducción- conformada por once trabajos de investigación de juristas alemanes, franceses y peruanos acerca de temáticas jurídicas ligadas a las nociones de democracia y de Estado de derecho. Cada contribución, que toma la forma de una reflexión académica de aproximadamente diez páginas, rinde cuenta de una realidad a partir de la especialidad de cada autor en materias tan distintas, pero complementarias, como la lucha contra la corrupción, la administración pública en su relación con el ciudadano o, de manera más puntual, los aportes de la jurisprudencia Lüth del Tribunal Constitucional peruano, la cual expresa que la Constitución de valores adquiere su legitimidad no por estar basada exclusivamente en la voluntad del pueblo, sino en el valor universal de la dignidad humana. Todo ello hace de esta publicación, probablemente, una de las de mayor valor teórico reciente para la teoría del derecho público, por lo que se recomienda su lectura a investigadores y estudiantes.

En lo formal, la obra se divide en cuatro secciones, antecedidas por una introducción a cargo del compilador de la obra. Dichas secciones son las siguientes: I. La estrecha relación entre el Estado de derecho, la democracia y los derechos fundamentales; II. Panorama e implicancias del Estado social de derecho; III. Garantías del Estado constitucional de derecho desde una perspectiva de derecho internacional y regional; IV. El tratamiento de algunos fenómenos que se confrontan con el Estado de derecho.

La primera contribución es una disertación del jurista Éric Millard. Dentro de lo complejo que resulta delimitar el tema para abrir paso a los demás artículos, se torna de lectura muy fluida al enfocarse en la acepción más común o aceptada de Estado de derecho, que, bajo un prisma kelseniano, sería la garantía de la democracia y de los derechos humanos. Además de ello, Millard identifica los tres modelos de Estado de derecho en la historia de las ideas constitucionales: el modelo liberal, el modelo material y el modelo formal, no sin comentar cada uno de estos, lo cual aporta mucha información al lector.

Algo resaltante que el lector apreciará en el presente libro es el caso Llanos Huasco, puesto que en esta sentencia el TC Peruano, en su evaluación, se vio 
desafiado con las dogmáticas de los derechos fundamentales, esto como una decisión sustancial basada en valores sujetándose al interés cognitivo común, ello tiene como referencia el caso Lüth de la Corte Constitucional Federal alemana. Esto no significa que hayan llegado a la misma decisión, ya que ambos tribunales constitucionales eligieron senderos diferentes. La contribución del caso alemán, caracterizado por la fusión entre el compromiso con la dignidad humana , por un lado, y la prevalencia de la Constitución, por otro -explicado por el jurista alemán Thilo Rensmann-, fue muy importante, no solo para el Perú, sino para muchos países en todo el mundo.

Además, se expone una idea de democracia y de ciudadanía administrativa, explicada por la doctora en Derecho Público Véronique ChampeilDespalts. Dicha noción se presenta en dos niveles. El primero es el terminológico, es decir, cómo se entiende la emergencia de nuevos términos en el vocabulario ligado con la organización y la actividad administrativa. El segundo nivel es el conceptual, pues se refiere a la cuestión de qué ciudadanía y de qué democracia se habla en materia administrativa.

El lector encontrará también un valioso aporte del doctor Carlos González, quien señala que, al movilizar los logros axiológicos y jurídicos de la teoría del Estado de derecho, se presentan dos tipos de críticas que contienen contradicciones e imprecisiones. El primero pretende que los derechos sociales deterioran la democracia, ya que imponen un modelo que aparentemente favorece el interés de clase y no el interés colectivo. El segundo invoca un retroceso de las libertades públicas con la llegada de un modelo de Estado llamado social, porque invade mucho la esfera privada. Tales críticas, sin embargo, tienen poco asidero, sostiene el autor, ya que la función del Estado social de derecho consiste en garantizar la libertad del individuo, concebida como una libertad limitada por los derechos civiles y también por otros, que son los derechos sociales. El individuo sacrificaría una parte de sus libertades como contraparte de una protección social. Se concluye, por ende - y de forma muy atinada-, que los derechos sociales constituyen un beneficio para el Estado de derecho porque permiten integrar a toda una sociedad en los valores de la democracia.

Una contribución trascendental es la que postula el jurista francés Manuel Tirard, quien señala que el Estado de derecho no solo debe analizarse desde un prisma netamente jurídico, sino que incluye también un prisma financiero estatal. Este se desagrega en las funciones de protección social, como la salud y la jubilación, las regulaciones del mercado laboral, los servicios públicos, 
o también las políticas de apoyo a la actividad y al empleo. Todas estas funciones representan actividades muy importantes para los habitantes de cualquier Estado, pero se encuentran ausentes o desatendidas. La demostración del doctor Tirard es de suma relevancia, ya que aporta más claridad acerca del funcionamiento del Estado social a través de una reflexión desde el derecho público financiero. Se trata de salir de la posición jurídica clásica que se propone estudiar los derechos sociales y recuperarlos en función de las necesidades reales, es decir, exponer cómo el derecho público financiero permite aportar una nueva visión.

En ese sentido, Manuel Tirard trata de explicar cómo las finanzas participan directamente en el funcionamiento del Estado social y en su existencia misma, además de demostrar que es posible encontrar diferentes modelos financieros de Estado social. También identifica dos elementos que determinan a partir de las finanzas cuál es —desde su punto de vista- la realidad de un Estado social: por un lado, el volumen de dinero extraído por los poderes públicos; $y$, por otro lado, la manera de repartir los ingresos públicos.

Asimismo, el autor destaca, basándose en dos modelos teóricos y políticos, que el Estado social francés es como una evolución del Estado social de derecho. Por un lado, el Estado social, caracterizado por su intervencionismo fiscal y económico con fines de redistribución de la riqueza y de los servicios; y, por otro lado, el Estado de derecho, caracterizado por el sometimiento de la acción pública a la regla del derecho y a la primacía de los derechos humanos. El autor se interroga sobre las formas, significado y consecuencias de esta transición de un Estado social a un Estado social de derecho, presentando primero el Estado social a la francesa y luego la emergencia de un Estado social de derecho.

Más adelante, atrae mucho la atención del lector la contribución del profesor alemán Jörg Menzel sobre la dignidad humana y la democracia, que constituyen el centro del derecho constitucional alemán y de otros ordenamientos jurídicos. El artículo de Menzel plantea cómo estos principios fundamentales han evolucionado entre sí e intenta determinar si es posible que la dignidad exista sin la democracia.

En el último capítulo del libro, el profesor griego Athanasios Gromitsaris analiza la corrupción como un fenómeno que sucede desde tiempos inmemorables y que se encuentra presente en todo el mundo; en ese sentido, define la corrupción como una acción que no es exclusiva de un solo Estado, porque refiere a aquel comportamiento que busca obtener favores o dinero para realizar 
o abstenerse de realizar un acto. Por ende, para luchar contra la corrupción se debe tratar de combatir o eliminar los obstáculos al buen funcionamiento del sector público y privado, ya que sin barreras ni dificultades burocráticas muchos individuos no tendrían razones para corromper. Más adelante, el autor discute de forma muy ordenada sobre los métodos, desde un prisma jurídico alemán, para iniciar reformas y superar las resistencias contra ellas.

A partir de ello, se señala que el Estado tiene que ser lo suficientemente fuerte para hacer valer el bien común sobre los intereses particulares; sin embargo, al mismo tiempo debe ser posible controlar y limitar al Estado para evitar el autoritarismo. El lector rescatará que un Estado de derecho que funciona bien representa una de las condiciones generales más importantes para el desarrollo económico, lo cual significa que la economía no es un asunto exclusivo del crecimiento económico.

En suma, se trata de una obra rica por la variedad de su contenido, pero también por la profundidad académica de cada demostración, que innova en sus postulados con la dialéctica jurídica muy conocida ya en el mercado latinoamericano. 